\title{
Psicodinâmica da mulher trabalhadora de meia-idade em fase de pré-aposentadoria
}

\author{
Marluce Auxiliadora Borges Glaus Leão ${ }^{1}$ \\ Joel Salles Giglio
}

\begin{abstract}
Resumo
Este estudo analisa o processo de aposentar-se como um fenômeno de transição na meia-idade, investigando como uma mulher trabalhadora, com alto nível de qualificação profissional, vivencia a proximidade da aposentadoria e o que orienta suas expectativas de vida. Utiliza entrevista e procedimento de desenhos-estórias como técnica de investigação clínica da personalidade, analisando qualitativamente os dados à luz da Psicologia Analítica. Constata que, nessa mulher, a proximidade da perda da identidade profissional, em virtude da aposentadoria, mobiliza símbolos que estão na sombra e que podem ser integrados à consciência, assim como arquétipos de transformação, determinando a qualidade de enfrentamento dessas mudanças na meia-idade. Conclui que o evento da aposentadoria propicia a redefinição e a reorientação da personalidade dessa mulher e que os programas de preparação para a aposentadoria devem destacar a importância dos aspectos psicológicos que esse evento envolve, favorecendo a continuidade do processo de individuação.

Palavras-chave: Aposentadoria; Mulher; Meia-idade; Psicologia Analítica.
\end{abstract}

\section{Psychodynamic of a middle age working woman in pre-retirement stage}

\begin{abstract}
This study analyses the retirement process as a phenomenon of transition in the middle life investigating how one working woman, with a high professional qualification level, faces the proximity of the retirement and the reorientation of her life expectations. An interview and drawing-stories procedures as a technique of personality clinical investigation were used, making a qualitative data interpretation under the framework of Analytical Psychology. It concludes that, in this woman, the proximity of professional identity loss, concerned to retirement mobilizes symbols which are in the shadow but can be integrated to consciousness, as well as transformation archetypes, determining in this way the quality of facing of the middle age changes. It also concludes that the retirement process propitiates a personality redefinition and re-orientation on this middle life woman. Preparation programs for retirement should be implemented in order to emphasize the psychological aspects brought by this event, promoting conditions for the continuity of the individuation process.
\end{abstract}

Keywords: Retirement; Woman; Midlife Crisis; Analytical Psychology.

\section{Introdução}

A aposentadoria pode ser vista como um evento normativo, na sociedade industrial. É esperada pelo indivíduo trabalhador ao longo de sua trajetória profissional e comporta, atualmente, vivências diferenciadas em relação à sua concepção original. Ou seja, significa não só proteção ao indivíduo que durante anos devotou sua vida ao trabalho, mas também um momento propício para redimensionar sua vida pós-trabalho.

A aposentadoria simboliza rupturas com realidades concretas de cunho político, social e econômico.
Este estudo circunscreve-se, no entanto, à aposentadoria como um fenômeno de transição para uma nova etapa da vida, analisando o impacto psicológico do processo de aposentar-se em cinco mulheres trabalhadoras de meia-idade, com alto nível de qualificação profissional. Reportamos, neste artigo, apenas um dos casos estudados.

A meia-idade é uma coorte etária bastante relevante para pesquisas, principalmente no que se refere às mulheres, pelas atuais exigências ambientais, desejo de progresso, integração e produtividade social de que são alvo, pelo aumento da expectativa de longevidade propiciada pela tecnologia médica e por

\footnotetext{
1 Texto derivado da dissertação de mestrado da autora, que contou com a orientação do prof. dr. Joel Salles Gíglio e com o apoio financeiro da Universidade de Taubaté/SP.

Endereço para correspondência:

Rua Rosa Barbieri Paiotti, 244 - Urbanova - São José dos Campos-SP - 12244-050

E-mail: sglaus@zipmail.com.br
} 
razões sociodemográficas das sociedades. $\mathrm{O}$ referencial da Psicologia Analítica de Carl Gustav Jung e seus sucessores é utilizado como suporte teórico na análise dos dados desta pesquisa, visando compreender em que medida os processos internos da personalidade são elementos críticos na determinação das transformações que a mulher experimenta nesse processo de transição, quais perspectivas orientam suas ações e estratégias para o futuro.

Mudanças nos padrões da aposentadoria e perspectivas na meiaidade

Do ponto de vista histórico, o trinômio aposentadoria-trabalho-velhice sempre esteve associado; entretanto, desde a década de 60 sofreu mudanças significativas em sua concepção, em face das questões mais amplas que permeiam a sociedade contemporânea. As mudanças no mundo do trabalho refletiram-se na aposentadoria, e a decisão de aposentar-se é influenciada muito mais pelos fatores externos, geralmente, sem nenhuma sincronia com os indicadores cronológicos que definem a etapa da velhice.

A revisão da literatura feita por Leão (2000), sobre os aspectos que determinam a decisão do trabalhador pela aposentadoria, mostra que a decisão voluntária ocupa as teorias mais recentes, indicando a aposentadoria como uma resposta racional aos incentivos financeiros, muito mais relacionada ao que o trabalhador deixará de perder no futuro. $\mathrm{Na}$ avaliação de Quinn \& Burkhauser (1990), as pesquisas atuais explicam essa decisão muito mais pelos fatores financeiros envolvidos, deixando de fora da equação o outro lado, ou seja, o comportamento de se aposentar.

Algumas pesquisas brasileiras envolvem esse último aspecto, sob diferentes perspectivas teóricas. Entre elas a de Deps (1994), que estuda a percepção de perdas e ganhos na transição à aposentadoria sob a ótica da teoria do curso da vida; a de Cecílio (1990), que faz uma análise psicossocial dos diferentes significados da aposentadoria, segundo o lugar do trabalho na vida do trabalhador e de como aposentadoria pode se confundir com velhice; e a de Santos (1990), que avalia a aposentadoria como perda do papel profissional, confrontação com a velhice e momento de reorganização da identidade pessoal.

Em relação às mulheres, os padrões de aposentadoria, conforme Jonhson \& Williamson (1987), pertencem a um conjunto de pesquisas negligenciado por muito tempo. Embora as pesquisas descritas por Leão (2000) correlacionem vários aspectos ao trinômio mulher-trabalho-aposentadoria, os aspectos relativos à psicodinâmica da mulher trabalhadora de meia-idade não se mostram contemplados. A questão psicodinâmica, no entanto, é relevante a estudos, quando consideramos a tendência registrada por Cockerham (1997), de crescimento da igualdade sexual no mercado de trabalho e conseqüente convergência das taxas de aposentadoria entre homens e mulheres; a carência de pesquisas sobre o comportamento de se aposentar referida por Quinn \& Burkhauser (1990) e ao descompasso teórico-metodológico na literatura sobre a transição da meia-idade e velhice em relação às demais fases do ciclo vital.

Em que pese o fato da meia-idade ser uma época de realizações interessantes e desafiadoras, um período de relativa estabilidade na vida, quanto a recursos pessoais, influência e produtividade, é também uma fase em que as pessoas, como refere Havighurst (1953), enfrentam várias dúvidas sobre sua capacidade física, mental, social e profissional e, tipicamente, essas pessoas lutam por manter aquilo que adquiriram na última década de suas vidas. Pode ser, ainda, uma época que coincide com o evento da aposentadoria e suas decorrências. Nesse sentido, tomamos aqui o termo meia-idade como maturidade, período de vida que vai aproximadamente dos quarenta aos sessenta anos de idade, em que maturidade significa "assumir uma atitude realista para com as mudanças que ocorrem dentro e fora de si mesmo, bem como a respeito dos seus ideais e objetivos na vida" (Rosa, 1982, p. 52).

Esse quadro multifacetado de vivências no período da meia-idade mostra-se mais complexo com a proximidade da aposentadoria, não só pelas turbulências das condições externas de seguridade e saúde, entre outros aspectos, mas também pelas questões internas que são reativadas, demandando uma reorientação da vida. Em virtude de todas essas vivências, grande parte das pesquisas recomenda os programas de preparação para a aposentadoria, ressaltando a importância de trabalhar profilaticamente essas perspectivas com o indivíduo, preparando-o para gerir de forma satisfatória seu tempo livre pós-trabalho e descobrir possibilidades de continuidade de autodesenvolvimento na nova etapa vivencial.

\section{O modelo de desenvolvimento psicológico do adulto segundo Jung}

A literatura científica registra que as bases para uma psicologia do desenvolvimento adulto foram estabelecidas na segunda metade do século XX, por diversos teóricos, que se empenharam em estabelecer modelos e teorias sobre as questões do ciclo vital, inclusive em relação ao envelhecimento, como por exemplo, Carl Gustav Jung. O modelo de desenvolvimento adulto de Jung (1930) e sua teoria da 
individuação foi escolhido para nortear a análise do estudo de caso desta pesquisa, que visa compreender as disposições psíquicas básicas da mulher de meia-idade ante seu momento de transição na vida, em virtude da proximidade da aposentadoria.

O esquema conceitual científico de Jung foi erigido concebendo a Psicologia como ciência humana, sendo influenciado pela perspectiva fenomenológica para a abordagem dos fatos psíquicos, privilegiando a relação do sujeito consigo mesmo. Jung vê a meta essencial do homem na interação psicológica fluente entre o ego e o self, feita principalmente por meio do processo de simbolização, em que o importante é o equilíbrio e o intercâmbio dinâmico entre o processo consciente e o inconsciente. Ou seja, a relação consciente/inconsciente possui uma característica organizadora e auto-reguladora da psique, com base no self, que atua tanto como um centro organizador, como também a totalidade da psique.

No tocante à psicologia do desenvolvimento, Jung dividiu o ciclo da vida em quatro etapas, concentrando menos interesse na infância e na velhice, preocupando-se mais com a idade adulta, particularmente na transição da meia-idade, e acreditando que a longevidade do homem não era aleatória: "Um ser humano certamente não viveria até os setenta ou oitenta anos se a sua longevidade não tivesse sentido para a espécie" (Jung, 1930, p. 349).

$\mathrm{Na}$ perspectiva de Jung, um novo processo de desenvolvimento interno começa na meia-idade, dando à segunda metade da vida um caráter diferente daquele que havia caracterizado a primeira metade. A esse processo denominou individuação, sua maior contribuição à psicologia do desenvolvimento. O termo refere-se ao desenvolvimento que começa no indivíduo adulto (embora a relação entre o ego e o inconsciente seja uma constante desde o nascimento até a morte), na maioria das vezes depois dos 35 anos de idade que, quando bem sucedido, conduz à descoberta do simesmo ou self. Jung definiu individuação como um "processo de desenvolvimento psicológico que faculta a realização das qualidades individuais dadas; em outras palavras, é um processo mediante o qual um homem se torna o ser único que é" (Jung, 1934, p. 50).

A transição da meia-idade é bastante difundida, em nossa cultura, como sendo um momento de crise, e nem sempre a ela se associa a oportunidade de redefinição ou reorientação da personalidade. É comum, segundo Hollis (1985, p. 24-25), nesse momento de transição os indivíduos se perguntarem diante do choque entre a personalidade adquirida e as exigências do si-mesmo: "Quem sou eu, além da minha história e dos papéis que representei?” Denomina essa transição de "passagem do meio", ocasião de redefinirmos e reorientarmos a personalidade: "A passagem do meio começa quando a pessoa precisa enfrentar questões até então evitadas (...). É muito mais uma experiência psicológica do que um evento cronológico."

Como os ritos de passagem na nossa sociedade tendem ao desaparecimento, este momento crítico na vida do indivíduo deixa a pessoa à deriva, pois exige "morrer para um estado anterior", ao mesmo tempo que acena com um renascimento para um novo estágio. Essa desorientação resultaria, por exemplo, na dissolução de projeções de conteúdos inconscientes e na insatisfação com a maneira como a pessoa está utilizando sua energia vital.

A atividade do trabalho é uma das tarefas típicas da idade adulta, um veículo fundamental para confirmarmos nossa identidade por meio do domínio do conjunto de nossas habilidades, uma possibilidade de transcendência por meio de nossas realizações. Contudo, geralmente as pessoas de meia-idade tendem a questionar o sentido do trabalho de toda uma vida, principalmente quando estão próximas da aposentaria.

Se, por um lado, isso nos mostra o esgotamento de uma área de projeção da identidade, por outro, pode ser a possibilidade de renascimento. Dessa insatisfação pode nascer a renovação. Se o trabalho ao qual o indivíduo se dedicou (como forma de manter uma situação economicamente viável para si e para a família) foi ao encontro de sua vocação (o que somos chamados a fazer com a nossa energia vital), o mistério do si-mesmo foi reverenciado. Com certeza a alma (compreendida como personalidade) foi atendida em suas necessidades, em detrimento da sedução de um ego muito mais socialmente orientado em suas necessidades (Hollis, 1985). A experiência consciente da "passagem do meio" requer que separemos quem nós realmente somos da soma das experiências que interiorizamos, quem sabe, com mais autenticidade, "para nos aproximarmos mais do nosso potencial e conquistarmos a vitalidade e a sabedoria do envelhecimento" (Hollis, 1985, p. 20).

\section{Método}

À época desta pesquisa de campo, algumas reformas na política previdenciária brasileira começavam a ocorrer, fazendo com que servidores públicos solicitassem contagem de tempo de serviço, avaliando a possibilidade de se aposentarem, receosos de sofrer 
perdas futuras. Entre maio e setembro de 1998, dezoito sujeitos procuraram o Setor de Aposentadorias e Pensões, de uma instituição pública localizada na região leste do Estado de São Paulo, aqui referida por X.

Descrevemos aqui um dos casos, analisado de forma qualitativa, em que o sujeito é por nós identificado como Ártemis, pela semelhança em termos arquetípicos com a psicodinâmica dessa deusa grega. Ártemis tem 45 anos, é casada, mora com o marido e tem dois filhos jovens. Ocupa o cargo de pesquisadora, tendo nível de escolaridade de pós-doutorado, sem outra atividade profissional paralela e com tempo de serviço de 28 anos, portanto, com direito ao benefício da aposentadoria proporcional, conforme a legislação brasileira vigente.

Os instrumentos utilizados foram a entrevista aberta, norteada por uma única pergunta: "Como você imagina que será sua vida depois de aposentada?", realizada no próprio local de trabalho do sujeito, com duração de 50 minutos; e a técnica de investigação de personalidade pelo procedimento do desenho-estória (D-E), de autoria de Walter Trinca (1997), instituído em 1972. Para a análise dos dados da entrevista, reportamonos ao método fenomenológico, examinando as experiências vividas e as significações a elas atribuídas pela entrevistada, a partir dos quatro momentos metodológicos preconizados por Giorgi (1985), sistematizando os dados por meio da redução, descrição e interpretação dos mesmos. A escolha do procedimento do desenho-estória objetivou a exploração dos aspectos inconscientes da personalidade pelo emprego de meios indiretos de expressão, permitindo uma sondagem abrangente da dinâmica psíquica do sujeito, na medida em que esse instrumento é, segundo Trinca, A. M. T. (1997), basicamente

\section{formado pela associação de processos expressivos motores (entre os quais se inclui o desenho livre) e processos aperceptivos-dinâmicos (verbalizações temáticas) (...) consiste de cinco unidades de produção, que são realizadas pelo examinando, sendo cada qual composta por desenho livre, estória, "inquérito" e título. (p. 13)}

Sua avaliação pode ser feita por diferentes referenciais teóricos, inclusive pela Psicologia Analítica, possibilitando resultados "representativos da forma de funcionamento mental de determinada população frente a uma situação especial" (Trinca, A. M. T., 1997, p. 52). Essa análise dos resultados do desenho-estória foi efetuada de forma globalística, que Tardivo (1997, p. 129) chama de análise por "livre inspeção de material".
Ou seja, partindo-se do conjunto da produção (desenhos, histórias, associações, etc.), identificam-se os motivos arquetípicos presentes, complexos afetivos mobilizados, conflitos subjacentes e instâncias de bloqueio (sombra), vivência de interação social e cultural do sujeito (persona), enfim, os principais símbolos constelados no eixo ego-self do sujeito. Todo esse material propiciou uma análise do desenvolvimento arquetípico-simbólico do sujeito estudado, que na visão de Byington (1988, p. 10) é o desenvolvimento da consciência por meio dos símbolos arquetípicos "empregando nessa função estruturante toda e qualquer vivência psíquica, seja ela de que natureza for". Em síntese, analisamos as transformações engendradas pelo inconsciente, em relação ao processo de individuação do sujeito, durante o processo de transição do trabalho à aposentadoria.

\section{Resultados e Discussão}

A seqüência do Desenho-Estória de Ártemis demonstra que ela possui energia psíquica disponível, bom nível intelectual e muita sensibilidade, percepção do mundo interior e exterior bem significativa, assim como maturidade afetiva marcante. Seus desenhos lembram a técnica do impressionismo, citada por ela própria como preferência de expressão artística, em que o jogo de luz e sombra ocupa espaço central. Ressaltamos o significado de impressionismo como expressão de um processo de interiorização, voltar-se para si próprio, ou conforme descrição de Ferreira (1986) "estilo literário e musical que se caracteriza por expressar, de maneira vaga, fluida e delicada, impressões subjetivas e ou sensoriais".

A natureza psíquica revelada por Ártemis, desde o início de sua entrevista e na produção do Desenho-Estória, deixa entrever características de um arquétipo relacionado à deusa evocada por seu nome fictício. Ela é a própria Ártemis no mundo moderno, sendo, portanto, uma deusa deslocada. Ou seja, aquela que não se sente verdadeiramente à vontade na cidade, por causa do ritmo acelerado e altamente tecnológico de vida e dos valores de ascensão social hoje vigentes. Ao refletir sobre a condição da futura aposentadoria, durante a entrevista, ela deixa muito claro esse desprendimento, referindo-se à forma como os colegas vêm se aposentando.

Eles acreditam que vão levar no momento em que se aposentarem, essa, vamos dizer assim, essa aura para fora de X, e que essa aura vai ajudá-los na vida lá fora. Então eles querem chegar, por exemplo, em qualquer

Psico-USF, v. 7, n. 2, p. 185-194, Jul./De₹. 2002 
lugar, e tipo assim: você sabe com quem está falando? Eu sou a doutora fulana de tal, de X, mas depois você não é mais.

Ártemis mostra sua natureza desde o primeiro desenho, em que é bastante clara a mobilização de seus aspectos afetivo-emocionais, ligados ao arquétipo materno, ao passado, um certo tom nostálgico e de grande expectativa quanto ao processo futuro, o que nos remete ao significado dos padrões arquetípicos descritos por Samuels, Shorter \& Plaut (1988, p. 39):

Padrões arquetipicos esperam o momento de se realizarem na personalidade (...) São dependentes da expressão individual e exercem uma fascinação reforçada pela expectativa tradicional ou cultural (...) Comportamentos arquetípicos têm a maior evidência em tempos de crise, quando o Ego está vulnerável ao máximo.

Retrata em seu primeiro desenho um bosque e intitula a história de "Um bosque para toda a vida", ficando evidente que sua produção é de transformação e de renovação. Ressalta a necessidade da morte como condição de vida, como num ciclo cósmico. Quando inquirida sobre a idade do bosque, ela diz que é um "bosque antigo, num clímax, mescla todos os estágios da vida, é um exemplo de renovação perpétua. Tem que dar luz e espaço para as árvores novas, morrendo uma árvore velha". Diz também que está "na borda da mata, olhando para ela em estado de enlevo, de veneração quase religiosa", que pode ser associado à palavra-chave para Ártemis que é natureza ou "divindade das matas" (Cirlot, 1984). Ela não se sente à vontade na cidade porque, no fundo, o seu lugar é nos campos e nas florestas. Com sensibilidade bastante desenvolvida, fala do bosque do seu desenho, também se reportando ao seu trabalho como pesquisadora, deixando entrever aspectos de sua estrutura interna, que, tal como as árvores, não se quebram ante as dificuldades.

Estava na Floresta Amazônica na última semana, observando com encanto a diversidade de padrões da natureza (...) a aparente similaridade comporta muita diversidade (...) a árvore é uma coisa aberta a circunstâncias, fica à mercê das intempéries, mas não se quebra.

Retira da natureza a energia para recompor-se, desde a tenra idade, ao dizer que "quando eu era criança, e queria ter um encontro comigo mesma, eu ia ao fundo do quintal, me encostava no muro e ficava quieta olhando as árvores. Depois de algum tempo eu voltava refeita das pequenas amarguras da infância." Ao mesmo tempo em que a cena evoca seu comportamento de infância, ela mostra conservar até hoje essa mesma forma de se restabelecer consigo mesma, repetindo-a na estória do segundo desenho, quando fala que sai de $\mathrm{X}$ à tarde, às vezes aborrecida, com problemas, magoada, "e chego na avenida e vejo o sol se pondo atrás da Mantiqueira. Vejo, e aquele momento me refaz, me distrai."

Coloca também a natureza como o aspecto mais importante da construção do segundo desenho, sob a temática "O sol e a serra", referindo ser uma espectadora e explicando que existem dois tipos de pessoas, quais sejam, "as que vivem e as que são espectadoras, as dionísiacas e as apolíneas. Eu sou uma pessoa objeto e sujeito, mais sujeito da observação do que objeto. (...) Se você me observar, eu vou estar sempre observando. Sou mais apolínea".

Em todas os desenhos, Ártemis deixa entrever um momento de sua vida em que está trabalhando muito consigo mesma, avaliando seus recursos internos, refletindo sobre o seu valor, em todos os seus contextos vivenciais, não só no nível profissional. Esse movimento pode ser entendido como a fluidificação do eixo ego-self, refletindo a fase da metanóia, do pesar o que foi feito, o que deveria ter sido feito, o que tem para ser feito, almejando uma integração de opostos, descobrindo-se como alguém vivo/inteiro contendo aspectos de luz e sombra. A metanóia, conforme Whitmont (1997, p. 86) "é um pré-requisito indispensável para a transformação que, entretanto, ocorre de forma espontânea no inconsciente e não pode ser causada diretamente por nenhum esforço deliberado de vontade..." Relatos da entrevista de Ártemis confirmam esse movimento.

Eu acho que o trabalho, ele sempre foi vital para mim (...) Eu não consegui nunca imaginar minha vida profissional fora dessa prisão. O trabalho sempre foi em primeiro lugar para mim (...) en não digo que tenha sido o primeiro lugar (...) mas vamos dizer assim, ele sempre foi muito importante, quer dizer, eu nunca fui uma pessoa que cogitei abandonar o meu trabalho porque tinha filhos. Eu digo que tive meus dois filhos enquanto eu estava fazendo meu doutorado, então, en fir. meu doutorado mais dois filhos juntos, foi um bruto de um sacrificio, talvez até então por isso foi muito forte.

Podemos nos reportar ao conceito de regressão de energia psíquica como elemento presente nos processos de transformação, como uma "temporária 
'perda de condição do Ego', a fim de levar à consciência e preencher uma necessidade psicológica até então não reconhecida" (Samuels e colaboradores, 1988), para explicar sua busca de análise psicológica, há três anos atrás, quando constatou que estava por sofrer grandes perdas, ao relatar que

\section{meus filhos agora já estão grandes (...) Então agora é como se tudo tivesse acabado na mesma época e o que tivesse sobrado tivesse sido novamente a profissão. Então, se eu me aposentasse... Há três anos atrás eu fui fazer análise por conta disso, porque quando eu tinha 25 anos de $X$, eu podia me aposentar, mas meus filhos estavam fazendo vestibular, e iam sair de casa e aí eu falei assim, nossa! Eu vou perder tudo de uma vez, en não vou dar conta disso, eu vou enlonquecer, então, aí, eu comecei a tomar consciência que eu tinha que retardar ao máximo minha aposentadoria para eu poder lidar com a coisa de ir perdendo aos poucos os papéis que você representa na vida, né? E ir se retirando da cena lentamente.}

Sob a égide do arquétipo da transformação, o confronto com aspectos da sombra também se mostra presente e necessário na produção de Ártemis, especialmente no terceiro e quinto desenhos. No terceiro desenho, intitulado "O vaso inadequado", Ártemis inicia identificando-se com o vaso. Tal qual o vaso, tem a sensação de que seu potencial não foi totalmente aproveitado. Esse sentimento de desajuste pode ser notado também no fato de ser o único desenho em que utiliza a folha em sentido vertical, denotando "liberdade em relação à ordem dada (...) e possível oposição ou negativismo" (Lourenção van Kolck, 1984, p. 7). Isso nos induz a pensar, então, em certa mobilização de situação conflituosa.

Enquanto desenha, critica sua falta de senso estético e lembra que, na adolescência, desejou ser estilista de moda, mas achou impossível, visto não saber desenhar. Essa preocupação tem a ver, geralmente, com a persona e com a valorização de aspectos da autoestima. Alternando um movimento de realçar, ora o vaso azul, ora as flores vermelhas, preocupa-se muito com o tamanho das flores, do quanto estão desproporcionais ao tamanho do vaso, acentuando seu colorido com a cor vermelha com espaços internos em branco.

No vaso do desenho, o vaso é grande para pouco conteúdo, para pouco uso, talvez isto possa ser uma visão ou sentimento da minha vida aqui em $X$ (...) men vaso existencial foi sempre subaproveitado (...) não por limitações externas apenas, por limitações internas também.
Essa dinâmica remete-nos também à ativação do sistema ego-persona, sugerindo dificuldades entre a identidade genuína e o papel social que exerce (Samuels, 1989), dificuldades, no entanto, que podem estimular o processo de individuação. A simbologia do vaso como depositário das possibilidades de transformação dos antigos alquimistas continua sendo por ela percebida.

O vaso é a vida. É um dado, a existência humana é dada sem controle, não escolhemos os pais, recebemos gratuitamente. Posso ser um vaso grande, pequeno, você não decide o tamanho do vaso que você é; por outro lado, o vaso tem uma qualidade frágil, por se quebrar, por deixar de ser vaso, tem uma analogia com a existência.

Essa dinâmica aparecerá outra vez no quinto desenho, quando dá à história o título de "Um bosque de pinus, para ocultar uma flor monstruosa". Enquanto desenha, fica incomodada com a flor vermelha feita inicialmente, procurando sobrepor à mesma uma árvore, utilizando por várias vezes a cor verde. A flor monstruosa é um aspecto de simbolização da sombra de sua personalidade. Ao ser encoberta por pinus (uma árvore que se adapta facilmente, tem rápido crescimento e é aproveitável), mostra possibilidade de flexibilização, descobertas, (re)adaptação, crescimento, desenvolvimento. Em termos prospectivos, parece indicar um processo de individuação em curso.

Constrói árvores (pinus) com copas em forma de vértices em direção ao céu, ao mental, ao espiritual, integrando, inclusive, a própria sombra. Dessa constatação surge uma nova flor, com as pétalas em branco e miolo cor-de-rosa, em destaque, com um caule em comum com outra flor idêntica. A natureza da deusa Ártemis mais uma vez se reflete em sua preferência pelo tipo de flor: "A flor da esquerda, com miolo cor-de-rosa, sou eu. É mais flor do campo, é um par e é nova, não está num lugar específico." Para essa situação conflituosa, o inconsciente propõe uma solução criativa, e Ártemis mostra sua própria natureza - é um par, uma união de opostos, um somatório de crescimentos, é nova, é (re)descoberta. Esse fato pode ser compreendido pela proposição de Samuels e colaboradores (1988, p. 138): "a situação de conflito, que não apresenta nenhuma solução racional ao dilema, é a situação na qual a oposição das 'duas' produz uma 'terceira' irracional, o símbolo". E o que também assinala Jung (1987, p. 118), "A ciência parece estacar junto às fronteiras da lógica, porém a natureza não 
vacila com os opostos; usa-os para criar, pela oposição, um novo nascimento."

No quarto desenho, "O Cais", Ártemis mostra a consciência que tem do processo interior de crescimento como ser humano, ao dizer que "Esta travessia é solitária, se passa internamente, não é compartilhada. Cada um chega ao seu cais, alguns chegam às falésias". Ela mesma vai contando a história e interpretando-a.

Simbolicamente pode ser assim: o barquinho corde-rosa sou eu, o oceano é a vida e o cais é o fim da existência, fazendo a travessia e deixando um pouquinho de nuvens para trás. A situação é que é uma situação pacífica, não é tormentosa (...) Este paredão dá a idéia de falésias, obstáculo intransponivel, mas a idéia de enseada é de recolbimento, pode apostar que vai encontrar uma transição segura do mar para a terra.

O paredão à esquerda simboliza o não poder voltar ao passado, nostalgia, expectativas quanto ao futuro, uma insegurança, uma ameaça ao controle da própria vida. Contudo, a enseada como função transcendente permite a transição de aspectos inconscientes (representados pelo mar) para a consciência (terra). A função transcendente sugere o fortalecimento do ego e uma nova atitude se torna disponível para a vida consciente, "serve de intermediária entre a pessoa e a possibilidade de mudança, fornecendo não uma resposta, mas sim uma escolha" (Samuels, 1989, p. 80). Esse renascimento, entretanto, só será possível na medida em que ela "morrer" para alguns processos que ainda incomodam, como a experiência de seus colegas que se aposentaram e que parecem não conseguir se adaptar à nova condição existencial, como relata na entrevista:

os aposentados viram uma espécie de almas penadas (...) vêm todos os dias a $X$ (...) ficam perambulando como se tivessem morrido, carregando as correntes do passado pelos corredores (...) é uma cena que quando vejo, eu sinto assim, muita pena, sabe, eu sinto uma compaixão imensa, porque eu me coloco assim, me projeto, né.

Ressente-se, também, do tratamento que os colegas de trabalho dão aos mais velhos e pressente que o mesmo poderá ocorrer com ela: "Até inconsciente é... eles boicotarem você, tirarem sua sala (...) não darem mais acesso, vamos dizer assim, enterrarem você em vida, sabe como é?" Assim como esse processo de transição é retratado na seqüência dos desenhos, na entrevista ele também pode se visto. Ártemis não está ainda pronta para morrer para essa fase da vida. Acha que

enquanto não estiver muito certa de que eu quero morrer eternamente aqui, que en quero me deixar matar pelos que ficam, então eu vou ficando, você entende? Enquanto não tirar, não desenraizar as coisas, (...) tirar, me libertar desse sentimento de que trabalhar em Xé vital para mim, porque, se não, o que vai acontecer? Eu vou definhar lá fora! A hora que eu cortar isso aí, en estaria cortando o oxigênio para manter o resto.

De novo é Ártemis quem fala. O "oxigênio", sua energia vital, precisa ser renovada eternamente, para o equilíbrio do sistema.

Em síntese, seu processo sugere mobilização do eixo ego-self, com consciência e recursos internos para viver essa jornada de forma saudável, simbolizado, no primeiro desenho, pelo tronco das árvores, onde as cascas e os nós (aspectos ligados ao tempo/ envelhecimento) relacionam-se com o seu mundo emocional, ou seja, desde o início mobilizou-se, e muito, o seu mundo afetivo-emocional. As clareiras no bosque, para que a luz do sol possa incidir (dinâmica da renovação, visto mostrar sempre o amanhecer), também podem representar um vazio que terá que ser preenchido, assim como o vaso do terceiro desenho, que, sendo "oco e vazio, permite a possibilidade de ser preenchido com diferentes conteúdos (...) coisas que podem dignificá-lo ou não".

Os símbolos mais marcantes de sua produção, portanto, reportam-nos à atuação da função transcendente, aquela que, segundo Sharp (1997, p. 75), "é em sua essência, um aspecto da auto-regulação da psique. Manifesta-se tipicamente, de modo simbólico, e é experimentada como uma nova atitude em face de si mesmo e da vida", também definida por Jung (1916. p. $1,23,189)$ como "A função psicológica e 'transcendente' resulta da união dos conteúdos conscientes e inconscientes (...) Aparece como uma das propriedades características dos opostos aproximados."

\section{Conclusão}

O discurso de Ártemis sugere uma atitude de introspecção, um voltar-se para si própria, questionando o sentido de tudo, numa avaliação do passado, do presente e do futuro, tentativas de compreensão mais profunda de seus valores e crenças quanto à vida, quanto a si mesma e aos outros. Percebe a aposentadoria como um momento em que pode escolher desfrutar dos direitos que esse evento lhe 
confere ou alçar novos vôos profissionais. Ártemis parece vivenciar a organização do trabalho como uma "grande mãe nutridora", que ameaça romper os laços com "seus filhos" por meio da aposentadoria. Ao promover essa separação, induz os mesmos à vivência da necessidade de uma separação simbólica de aspectos da personalidade que nortearam suas vidas até então.

Esse processo de transição do trabalho à aposentadoria deflagrou em Ártemis um movimento de morrer para alguns processos vivenciais de (re)nascer, para outros, num movimento de busca de integração dos aspectos opostos da personalidade, rumo à individuação. $\mathrm{O}$ desconforto provocado por esse processo conduziu Ártemis a buscar um profissional para ajudá-la em sua análise pessoal, há três anos, conforme seu próprio relato. Essa necessidade, segundo ela, coincidiu com a saída dos filhos adolescentes de casa e a possibilidade de já se aposentar por tempo proporcional, se desejasse, quando estava com 43 anos de idade, por ter ingressado na carreira profissional muito jovem.

Em sua trajetória de vida, o papel profissional foi muito importante. No momento em que podia ser descartado e/ou substituído, ela percebeu a posição central do mesmo em sua vida, e percebeu também que sua perda coincidia com a perda de outro papel, o de mãe, o que a deixou perplexa: "É como se tudo tivesse acabado na mesma época, e o que tivesse sobrado, tivesse sido novamente a profissão; então, se eu me aposentar...".

Essa constatação mobilizou Ártemis, induzindoa a retardar ao máximo a aposentadoria, para poder lidar com essas perdas. A necessidade de ir se retirando de cena, aos poucos, simboliza o processo de enfrentamento de questões até então evitadas. A necessidade de uma reorientação de vida, demandada pelo self, começou a ser avaliada pelo ego. Ou seja, Ártemis, quando faz um balanço da perda do papel profissional a partir da aposentadoria, observa algumas sinalizações do mundo externo. Por exemplo, tem consciência de ser uma pessoa dispensável ao dizer, "foi a primeira vez que eu tive a consciência de quanto você é dispensável, que aquele ditado estava certo, que o homem é uma laranja que você chupa e joga o bagaço fora". O sofrimento advindo desse balanço aparece em seu relato sobre como as pessoas com as quais trabalhou, ou que ajudou a formar, e pelas quais tem o maior carinho, ao se preocuparem com a sua saída, faziam-no como quem ia ficar com o espólio.

Então começaram em vida, como se eu fosse uma "tia velha", começaram a lançar a sorte sobre os meus bens. E aí, eu pensei: Nossa, que horror que é. Isso não é uma coisa para se comemorar com a aposentadoria (...) Foi um negócio que me deixou profundamente abalada.

A percepção de si mesma e de seu valor, com base nesses aspectos externos, desencadeou em Ártemis uma necessidade mais profunda de avaliação de quem era ela e dos papéis que representara até então, culminando em uma clara percepção de que tem que morrer para esse papel. Cita, inclusive, o exemplo da morte, há pouco tempo, de um eminente profissional, que acredita ter sido resultado do ostracismo a que foi relegado, "Justamente por não ter se preparado psicologicamente para o fato de que você deixa de ser o que é, quando se aposenta, uma parte de você é roubada, quer dizer, roubada não, tirada de você."”

Portanto, a consciência da necessidade de preparar-se psicologicamente para aposentar-se começa a ser delineada por ela e confirmada quando comenta que "É porque eu justamente não consigo imaginar minha vida depois de aposentada é que eu não me aposentei." Essa vivência de alguma forma perturba Ártemis, aprisiona-a em seu desejo de aproveitar-se melhor do potencial que possui, do conteúdo que ela, enquanto "vaso", tem para explorar e que denuncia quando fala "Como eu nunca consegui imaginar minha vida profissional fora dessa prisão, de $\mathrm{X}$, eu tenho evitado a idéia de me aposentar."

Ártemis é uma presa de sua própria armadilha: "Eu não consigo me imaginar fazendo outra coisa que não seja o que eu faço aqui em $\mathrm{X}$, porque é uma coisa que eu venho fazendo com tanto prazer, há tanto tempo." Isso nos induz a pensar, tal como Sharp (1997, p. 10), na prisão como um símbolo familiar para o analista, de recusa do processo de individuação. Nesse sentido, parafraseando essa mesma autora, Ártemis encontra-se trancada em sua própria psique, apenas consigo mesma como carcereira, na medida em que também vê a aposentadoria como "passaporte para o fim, é o fim da carreira, fim de linha, é o fim".

Contudo, Ártemis escolheu a jornada do herói. Desejou, quando buscou a análise, não ser igual a alguns de seus colegas que se aposentaram e morreram para a vida, tornaram-se "fantasminhas, plufts" (sic), visitando sempre a instituição, sem conseguir se desligar dela. Ao retratar-se como um vaso inadequado (3o desenho), que foi subaproveitado em seu potencial, poderia ter se identificado com a síndrome do "pobre de mim", característica do desejo regressivo de dependência, de volta ao passado e estagnação em termos de 
individuação. Mas Ártemis optou por embarcar numa aventura heróica, começou a fazer a travessia, tentou encontrar seu tesouro, compreender seus verdadeiros sentimentos, seu potencial único.

Essa travessia, agora, mostra-se mais serena (quarto desenho), percebe-se arrastada para um futuro desconhecido, mas "sabe" que chegará a um "porto seguro" (sic). Finalmente, no quinto desenho, surge uma experiência psíquica de natureza potencialmente criativa, uma nova vida, com novas possibilidades simbolizadas pelo par de flores. Em seu "bosque para esconder uma flor monstruosa", desenha duas flores jovens a partir de um único caule, demonstrando que "uma nova atitude se torna disponível para a vida consciente e, ao mesmo tempo, a própria consciência do ego é fortalecida" (Samuels, 1989, p. 80). Tenta se ajustar à nova vida, continua a trabalhar em si mesma essas transformações e mostra-se mais forte em todos os sentidos.

Todo o processo de Ártemis demonstra, portanto, uma crise da meia-idade, uma tentativa de auto-ajuste diante de uma situação vivencial de mudanças em vários níveis, mas em que, principalmente, a aposentadoria representa a ativação dos opostos vida/morte, exigindo uma integração dos conteúdos do inconsciente, que favorecem as possibilidades de individuação. Essa psicodinâmica de Ártemis vem corroborar com a perspectiva da Psicologia Analítica, de que o conflito na meia-idade, quando trabalhado, pode ceder lugar a uma intervenção criativa e a uma reorientação do self. A crise da meia-idade, chamada por Hollis (1985, p. 9) de "passagem do meio", pode ser "A ocasião de redefinirmos e reorientarmos nossa personalidade, num ritual de passagem entre a adolescência prolongada da primeira idade adulta e o nosso inevitável encontro com a velhice e a mortalidade." Nesse sentido, ratificamos a importância dos Programas de Preparação para a Aposentadoria, suas orientações legais, econômico-financeiras, sociais e culturais, mas, principalmente, a orientação psicológica, assegurando aos pré-aposentandos condições favoráveis à continuidade do processo de individuação.

Concluímos que, para a mulher trabalhadora de meia-idade deste estudo, a aposentadoria mostrou-se um evento contraditório, por colocar fim, pelo menos do ponto de vista normativo, à aventura heróica de dedicação à carreira profissional que desde cedo empreendeu. Questionou se desejava resgatar papéis relegados a um segundo plano em razão do trabalho ou, ainda, se cumpria com a meta essencial do feminino na sociedade, de resgatar valores, crenças e atitudes básicas de solidariedade, hoje tão necessárias à humanidade.

\section{Referências}

Byington, C. (1988). Estrutura da personalidade: sombra e persona. São Paulo, SP: Ática.

Cecílio, S. (1990). Aposentadoria como velbice: um subproduto do culto ao trabalho? (Dissertação de Mestrado). São Paulo: Pontifícia Universidade Católica - Departamento de Psicologia Social.

Cirlot, J. E. (1984). Dicionário de símbolos. São Paulo, SP: Moraes.

Cockerham, W. C. (1997). Work and retirement. Em This aging society. 2. ed. New Jersey: Printice-Hall.

Deps, V. L. (1994). A transição à aposentadoria na percepção de professores recém-aposentados da Universidade Federal do Espírito Santo (Tese de Doutorado). Campinas: Universidade Estadual de Campinas - Faculdade de Educação.

Ferreira, A. B. H. (1986). Novo dicionário da língua portuguesa. 2. ed. Rio de Janeiro: Nova Fronteira.

Giorgi, A. (1985). Phenomenology and psychogical research. Pittsburgh: Dusquene University.

Havighurst, R. J. (1953). Human development and education. New York: David Mckay Co.

Hollis, J. (1985). A passagem do meio: da miséria ao significado da meia-idade. São Paulo, SP: Paulus.

Jonhson, E. S. \& Williamson, J. B. (1987). Retirement in the United States. Em Markides, K. S.; Cooper, C. L. (Orgs.). Retirement in industrialized societes. New York: Wiley.

Jung, C. G. (1912). Symbols of transformation. London: Routhedge \& Kegan Paul. CW, v. V. 1956.

Jung, C. G. (1916). A Função Transcendente. Em Jung, C. G. A natureza da psique. 3. ed. Petrópolis, RJ: Vozes, v. VIII/2, p. 1-23, 1991.

Jung, C. G. (1930). As etapas da vida humana. Em Jung, C. G. A natureza da psique. 3. ed. Petrópolis, RJ: Vozes, v. VIII/2, p. 335-353, 1991.

Jung, C. G. (1934). Individuação. Em Jung, C. G. O eu e o inconsciente. 5. ed. Petrópolis, RJ: Vozes, v. VII/2, p. 49-115, 1985.

Jung, C. G. (1944). Psicologia e alquimia. Petrópolis, RJ: Vozes, v. XII, p. 51, 1991. 
Jung, C. G. (1948). A sombra. Em Jung, C. G. Aion: estudos sobre o simbolismo do si-mesmo. Petrópolis, RJ: Vozes, v. IX/2, p. 6-8, 1994.

Jung, C. G. (1987). A prática da psicoterapia. Petrópolis, RJ: Vozes, v. XVI/2, p. 118.

Leão, M. A. B. G. (2000). Aposentadoria como perspectiva de individuação em mulheres trabalhadoras de meia-idade (Dissertação de Mestrado). Campinas: Universidade Estadual de Campinas - Faculdade de Ciências Médicas.

Lourenção Van Kolck, O. (1994). Testes projetivos gráficos no diagnóstico psicológico. Em Rappaport, C. R., (Coord.). Temas básicos de Psicologia. São Paulo, SP: EPU, v. 5.

Quinn, J. F. \& Burkhauser, R. V. (1990). Work and retirement. Em Binstock, R. H.; George, L. K. Handbook of aging and the social sciences. San Diego: 3. ed.

Rosa, M. (1982). Psicologia evolutiva: psicologia da idade adulta. Petrópolis, RJ: Vozes, v. 4. p. 52-74.

Samuels, A. (1989). Jung e os pós-junguianos. Rio de Janeiro, RJ: Imago.
Samuels, A., Shorter, B. \& Plaut, F. (1988). Dicionário crítico de análise junguiana. Rio de Janeiro, RJ: Imago.

Santos, M. F. (1990). Identidade e aposentadoria. São Paulo, SP: EPU.

Sharp, D. (1997). Léxico junguiano: dicionário de termos e conceitos. São Paulo, SP: Cultrix.

Tardivo, L. S. C. (1997). Análise e interpretação. Em Trinca, W. (Org.). Formas de investigação clínica em psicologia. São Paulo: Vetor. Parte II, Cap. 6, p. 115-156.

Trinca, A. M. T. (1997). Ampliação e expansão. Em Trinca, W. (Org.). Formas de investigação clínica em psicologia. São Paulo: Vetor. Parte I, Cap. 2, p. 35-66.

Trinca, W. (Org.). (1997). Apresentação e aplicação. Em Trinca, W. Formas de investigação clínica em psicologia. São Paulo: Vetor. Parte I, Cap. 1, p. 11-34.

Whitmont, E. C. (1997). A busca do símbolo: conceitos básicos de psicologia analítica. 10. ed. São Paulo, SP: Cultrix.

Recebido 22/08/2002

Revisado em 19/11/2002

Aceito em 10/12/2002

Sobre os autores:

Marluce Auxiliadora Borges Glaus Leão é psicóloga, mestre e doutoranda em Ciências Médicas pela Faculdade de Ciências Médicas da Universidade Estadual de Campinas, professora colaboradora do Curso de Psicologia da Universidade de Taubaté e coordena o Programa de Atenção Integral ao Idoso.

Joel Salles Gíglio é médico psiquiatra, professor doutor no Departamento de Psicologia Médica e Psiquiatria da Faculdade de Ciências Médicas da Universidade Estadual de Campinas, membro da Associação Jungueana do Brasil. 